\title{
Papers
}

\section{Empirical prescribing for dyspepsia: randomised controlled trial of test and treat versus omeprazole treatment}

\author{
Gianpiero Manes, Antonella Menchise, Claudio de Nucci, Antonio Balzano
}

\begin{abstract}
Objective To compare the efficacy of a "Helicobacter pylori test and treat" strategy with that of an empirical trial of omeprazole in the non-endoscopic management by empirical prescribing of young patients with dyspepsia.

Design Randomised controlled trial.

Setting Hospital gastroenterology unit.

Participants 219 patients under 45 years old presenting with dyspepsia without alarm symptoms. Intervention Patients received treatment with omeprazole $20 \mathrm{mg}$ (group A) or with a urea breath test followed by an eradication treatment in case of $H$ pylori infection or omeprazole alone in non-infected patients (group B). Lack of improvement or recurrence of symptoms prompted endoscopy. Main outcome measures Improvement in symptoms assessed by a dyspepsia severity score every two months; use of medical resources (endoscopic workload and medical consultation); clinical outcome. Results 96/109 (88\%) patients in group A and $61 / 110(55 \%)$ in group $\mathrm{B}(\mathrm{P}<0.0001)$ had endoscopy: in 19 patients in group A and 32 in group B (20/67 infected and 12/43 non-infected) because of no improvement; in 77 further patients in group A and 29 in group B (7 infected and 22 non-infected) because of recurrence of symptoms during follow up. Endoscopy showed peptic ulcers only in group A; oesophagitis occurred significantly more often in group B than in group A. About $80 \%$ of examinations were normal in both groups, but nine duodenal scars occurred in group A.

Conclusions Eradication treatment allows resolution of symptoms in a large number of patients with dyspepsia and reduces the endoscopic workload. After a trial of omeprazole, symptoms recur in nearly every patient. Such treatment is also likely to mask an appreciable number of peptic ulcers and cases of oesophagitis.
\end{abstract}

\section{Introduction}

Dyspepsia is a common condition in the general population of industrialised countries. The increasing cost of treatments for dyspepsia has led to a search for alternative management strategies. Substantial agreement exists that patients older than 45 with dyspeptic symptoms and patients with alarm symptoms (symp- toms suggestive of underlying malignancy) should undergo endoscopy, but case selection on the basis of empirical treatments has been proposed for young patients in order to reduce endoscopic workload. ${ }^{1-4}$ The American College of Physicians recommended a trial of an $\mathrm{H}_{2}$ antagonist for patients presenting with dyspepsia, reserving endoscopy for relapsers and nonresponders. ${ }^{1}$ Subsequent trials have shown that proton pump inhibitors produce a better outcome than $\mathrm{H}_{2}$ antagonists, presumably as a result of better treatment of reflux. ${ }^{5}$

Infection with Helicobacter pylori can be diagnosed non-invasively. Eradication of the infection definitively cures the vast majority of peptic ulcers. ${ }^{6}{ }^{7}$ In industrialised countries people under the age of 45 who are not taking non-steroidal anti-inflammatory drugs are unlikely to be affected by serious gastroduodenal disease if they have a negative $H$ pylori test. On the basis of these observations, the European $H$ pylori Study Group advised that young dyspeptic patients without alarm symptoms and found to be infected by means of non-invasive tests should receive empirical eradication treatment without endoscopy. ${ }^{3}$

Initial empirical strategies in the management of dyspepsia have been evaluated from an economic standpoint with somewhat controversial results. ${ }^{8-11}$ The cost effectiveness of these strategies depends on the cost of endoscopy, as well as on the prevalence of peptic ulcer disease and functional dyspepsia in the population of dyspeptic patients. A reduction in endoscopic workload by the application of clinical selection criteria to endoscopy is, however, advisable, even if this does not have a cost benefit.

To date, no published prospective fully randomised trials have compared the efficacy of the "test and treat" strategy with that of empirical treatment with a proton pump inhibitor in a clinical setting as an initial management strategy for dyspeptic patients. We aimed to conduct such a trial.

\section{Methods}

Participants

We studied outpatients with symptoms of dyspepsia referred by their general practitioners to our department over a two year period. We included young adults (18-45 years of age) presenting with uninvestigated upper abdominal symptoms. Exclusion criteria were age less than 18 years, alarm symptoms,
Department of Gastroenterology, Cardarelli Hospital, Via Solimena 101 , 80129 Naples, Italy Gianpiero Manes consultant gastroenterologist Antonella Menchise specialist registrar in gastroenterology

Claudio de Nucci consultant gastroenterologist Antonio Balzano director

Correspondence to: G Manes gimanes@tin.it

bmj.com 2003;326:1118 
symptoms of gastro-oesophageal reflux disease, regular use of non-steroidal anti-inflammatory drugs, previous surgery to the upper gastrointestinal tract, pregnancy, and treatment with antibiotics, proton pump inhibitors, or $\mathrm{H}_{2}$ antagonists in the previous four weeks. We invited patients fulfilling the entry criteria to enter the study and obtained written informed consent.

We assessed symptoms at baseline by means of a previously validated questionnaire. ${ }^{12}$ We stratified the randomisation procedure to take into account sex, tobacco use, and alcohol intake in the previous two years (social intake $\leq 80 \mathrm{~g} /$ day in men, $\leq 50 \mathrm{~g} /$ day in women; excess intake $>80 \mathrm{~g} /$ day in men, $>50 \mathrm{~g} /$ day in women). We used a computer generated list to randomly assign patients to either empirical treatment with omeprazole $20 \mathrm{mg}$ /day for four weeks (group A) or a ${ }^{13} \mathrm{C}$-urea breath test for $\mathrm{H}$ pylori (group B). Patients whose $H$ pylori test showed no infection received four weeks' treatment with omeprazole $20 \mathrm{mg}$ /day. Infected patients received one week of triple eradication treatment (omeprazole $20 \mathrm{mg}$, clarithromycin $500 \mathrm{mg}$, and tinidazole $500 \mathrm{mg}$, all twice daily). We tested for $H$ pylori again at the four week review and gave a further course of treatment if the test was positive.

We saw participants at the outpatient clinic four weeks after the first visit. We asked them to describe their symptoms, as well as to compare their symptoms with those at entry (no symptoms, improvement in symptoms, no change, or worse symptoms) and to state their satisfaction with their medical care. We administered the same questionnaire again. Patients who had improved symptoms at the four week visit entered the follow up phase. If symptoms had not improved we offered endoscopy, which we performed at least two weeks after the visit in order to reduce the rate of false negative $H$ pylori test results.

\section{Follow up and outcome assessment}

An investigator who was blinded to group assignment followed up participants every two months for one year or when symptoms recurred. We contacted each patient by telephone, requesting them to attend for reassessment. In a face to face interview, the investigator asked patients to describe their symptoms and to compare them with those at entry. We used the same questionnaire that had been administered at baseline to assess symptoms.

We defined a relapse as the recurrence of symptoms as judged by the patient on a four point Likert-type scale (no symptoms, improvement in symptoms, no change, worse symptoms). This was the primary endpoint of the trial. We offered endoscopy to patients who relapsed.

\section{Endoscopy}

We performed endoscopy in the usual manner, paying particular attention to the recognition of hiatus hernia, which we defined as a circular extension of gastric mucosa of more than $2 \mathrm{~cm}$ above the diaphragm. ${ }^{13}$ During the examination we took antral and corpus biopsies for rapid urease testing and histology. We classified patients as positive for $H$ pylori infection if the rapid urease test or histology was positive in the antrum or body. We defined oesophagitis according to a modified Savary and Miller classification by the presence of a break in the oesophageal mucosa. ${ }^{14}$

\section{Statistical analysis}

The primary endpoint of the study was recurrence of symptoms. We assessed the rate of patients undergoing endoscopy as well as the time to first relapse. With a type I error of $5 \%$ and a power of $90 \%$, the planned study of 204 patients (102 for each group) could detect a difference of 0.25 in the rate of patients undergoing endoscopy and of 50 in the mean number of days without symptoms in each group (we assumed a standard deviation of 110). A secondary outcome measure was difference in mean change in the dyspepsia severity score $(90 \%$ power to detect 0.6 difference).

We analysed the data by using life table methods and compared the remission curves of the two groups by using the log rank test. We used the Mann-Whitney $\mathrm{U}$ test to compare symptom scores between the groups and the $\chi^{2}$ test to compare categorical variables. All analyses were intention to treat, and we took a $\mathrm{P}$ value of $<0.05$ as statistically significant.

\section{Results}

Between November 1998 and November 2000 we assessed 765 patients with dyspepsia. Of these, $522 \mathrm{did}$ not meet the inclusion criteria. We excluded two patients because they did not live in the country; 22 eligible patients declined to participate. We recruited a total of 219 patients. Figure 1 shows the trial profile. We randomised 109 patients to treatment with a proton pump inhibitor (group A) and 110 to a urea breath test (group B). Sixty seven (61\%) patients in group B tested positive for $H$ pylori and received eradication treatment. The other $43 \mathrm{had}$ a negative result and received omeprazole. Baseline characteristics of the two groups were similar (table 1). The $H$ pylori infection was eradicated in 63 patients in group B after the first treatment (eradication rate 94\%) and in four patients after second line treatment. All patients identified for follow up were successfully reassessed. However, one patient in group A, whose symptoms recurred after four months, arbitrarily took omeprazole $20 \mathrm{mg}$ for five days before being re-evaluated;

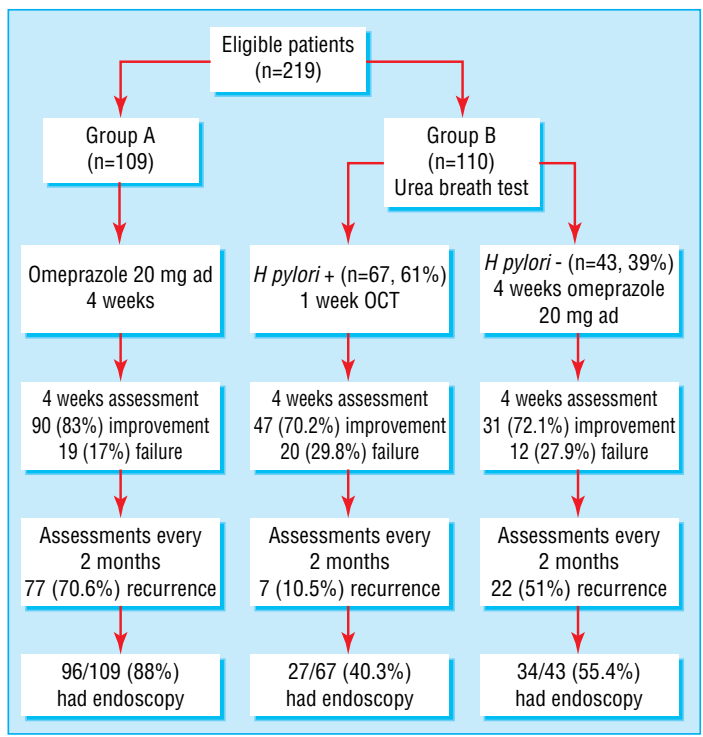

Fig 1 Trial profile $(O C T=$ eradication treatment with omeprazole, clarithromycin, and tinidazole) 
endoscopy showed an $H$ pylori positive duodenal ulcer. Two other patients, one in each group, did not attend the first follow up visit but attended the remaining visits; they remained symptom free during the follow up. Another patient in group B was unable to attend the final visit because he had moved out of the country. We contacted him by telephone, and he confirmed the absence of symptoms. We did not exclude any patient from the final analysis.

\section{Clinical efficacy and endoscopic assessment}

Ninety $(83 \%, 95 \%$ confidence interval $74 \%$ to $89 \%)$ patients in group A and $78(71 \%, 61 \%$ to $79 \%)$ in group B described improvement in symptoms at the four week visit $(\mathrm{P}=0.05$, not significant) and entered the follow up. In group B, 47 (70\%) of the 67 H pylori positive patients and $31(72 \%)$ of the $43 \mathrm{H}$ pylori negative patients had improved symptoms. Eight of the 20 $H$ pylor $i$ infected patients who still had symptoms at the four week visit had, however, noted improvement of their symptoms during the one week treatment and then relapsed after stopping treatment.

Of the 109 patients randomised to empirical omeprazole treatment (group A), 19 (17\%, 11\% to $26 \%$ ) proceeded to endoscopy after the first review because of lack of improvement. Nine $(47 \%)$ of these were infected. Endoscopy was normal in all patients, but six had hiatus hernia. Seventy seven further patients $(71 \%$, $61 \%$ to $79 \%$; $51(66 \%) H$ pylori positive) who had improved symptoms at the four week visit underwent endoscopy during the follow up because of recurrence. Endoscopy showed oesophagitis in four patients, duodenal ulcer in 15 , and gastric ulcer in one. Nineteen patients had hiatus hernia. Overall, 96 patients $(88 \%$, 0.8 to 0.93 ) in group A had an endoscopy during the study (table 2).

Of the $67 \mathrm{H}$ pylori positive patients randomised to empirical eradication treatment $20(30 \%, 19 \%$ to $42 \%)$ proceeded to endoscopy after the first visit because of the presence of symptoms. Endoscopy showed hiatus hernia in nine patients and oesophagitis grade I in three patients; no patient was infected. Seven $(10 \%, 4 \%$ to $20 \%$ ) further patients had endoscopy during follow up because of recurrence of symptoms. Endoscopy showed oesophagitis grade I in two patients; four patients had hiatus hernia. Overall, 27 (40\%, 28\% to 53\%) patients in the eradication group had an endoscopy $(\mathrm{P}<0.0001$ compared with group A). Twelve (28\%, $15 \%$ to $44 \%)$ out of $43 \mathrm{H}$ pylori negative patients were referred for endoscopy after the first visit; they all had a normal endoscopy, except for three with hiatus hernia, and all patients were negative for $H$ pylori. Twenty two $(51 \%$,
Table 1 Baseline characteristics of the study groups

\begin{tabular}{lcc} 
& $\begin{array}{c}\text { Group A-proton pump } \\
\text { inhibitor alone }(\mathbf{n = 1 0 9 )}\end{array}$ & $\begin{array}{c}\text { Group B-eradication of } \\
\text { Helicobacter pylori }(\mathbf{n}=\mathbf{1 1 0})\end{array}$ \\
\hline Mean (range) age (years) & $38(19-45)$ & $38.9(18-44)$ \\
\hline Sex (male/female) & $61 / 48$ & $59 / 51$ \\
\hline Smokers (No (\%)) & $44(40)$ & $45(41)$ \\
\hline $\begin{array}{l}\text { Alcohol drinkers (excess intake) } \\
\begin{array}{l}\text { Mean (95\% Cl; range) symptom scores } \\
\text { at baseline }\end{array}\end{array}$ & 0 & 0 \\
\hline
\end{tabular}

$36 \%$ to $67 \%$ ) further patients had an endoscopy during follow up because of recurrence of symptoms. Endoscopy showed reflux oesophagitis grade I in four patients and hiatus hernia in 10; all patients were negative for $H$ pylori (table 2). Overall, 61 (55\%, 46\% to $65 \%$ ) patients in group $\mathrm{B}$ had an endoscopy during the study $(\mathrm{P}<0.0001$ versus group $\mathrm{A})$ (table 2$)$.

Table 2 shows the diagnoses found by endoscopy in the patients in the two groups. No peptic ulcer occurred in group B; the prevalences of hiatus hernia and oesophagitis were significantly higher in the patients in group B who had an endoscopy. Interestingly, among the patients who did not show active lesions at endoscopy, nine (9\%) in group A and none in group B showed a scar in the duodenal bulbus $(\mathrm{P}<0.05)$.

\section{Symptom assessment}

Figure 2 shows the mean dyspepsia scores over the various time points of the study. The dyspepsia score was significantly better in the proton pump inhibitor group then in the test and treat group at the first follow up visit but became significantly worse at six and 12 months. In the test and treat group, but not in the proton pump inhibitor group, the dyspepsia score at the 12 month review showed significant improvement compared with baseline $(\mathrm{P}<0.0001)$.

\section{Relapses between 0 and 12 months}

Life tables show the days to relapse of symptoms after successful treatment in patients in the two groups (fig 3). The proportion of days (number of days per patient) without symptoms was significantly higher in the test and treat group than in the proton pump inhibitor group (mean 231.5 (95\% confidence interval 205.7 to 257.2 ) v 139.3 (117.9 to 160.7 ); $\mathrm{P}<0.001$ ), even including in the first group the $H$ pylori negative patients who received omeprazole. When symptomatic relapse occurred, it occurred earlier (usually in the first two months) in the patients who received $H$ pylori eradication treatment than in the proton pump inhibitor group: four (57\%) of seven patients with eradication

Table 2 Diagnoses by upper gastrointestinal endoscopy in each of the two study groups. Values are numbers (percentages) unless stated otherwise

\begin{tabular}{|c|c|c|c|c|c|}
\hline \multirow[b]{2}{*}{ Diagnosis* } & \multicolumn{2}{|c|}{ Group A—proton pump inhibitor alone } & \multicolumn{2}{|c|}{ Group B-eradication of Helicobacter pylori } & \multirow[b]{2}{*}{$P$ value } \\
\hline & Total & H pylori positive & Total & H pylori positive & \\
\hline Patients who had endoscopy & 96 & $60(63)$ & 61 & 0 & \\
\hline Duodenal ulcer & $15(16)$ & $13(87)$ & 0 & 0 & $<0.001$ \\
\hline Gastric ulcer & $1(1)$ & $1(100)$ & 0 & 0 & NS \\
\hline Oesophagitis & $4(4)$ & $2(50)$ & $9(15)$ & 0 & 0.03 \\
\hline Normal & $76(79)$ & $44(58)$ & $52(86)$ & 0 & NS \\
\hline Hernia & $25(26)$ & $14(56)$ & $26(43)$ & 0 & 0.03 \\
\hline Duodenal scar & $9(9)$ & $9(100)$ & 0 & 0 & 0.01 \\
\hline
\end{tabular}

NS=not significant

${ }^{\star}$ More than one diagnosis is possible; endoscopies showing hiatus hernia or scar without other lesions were considered to be normal. 


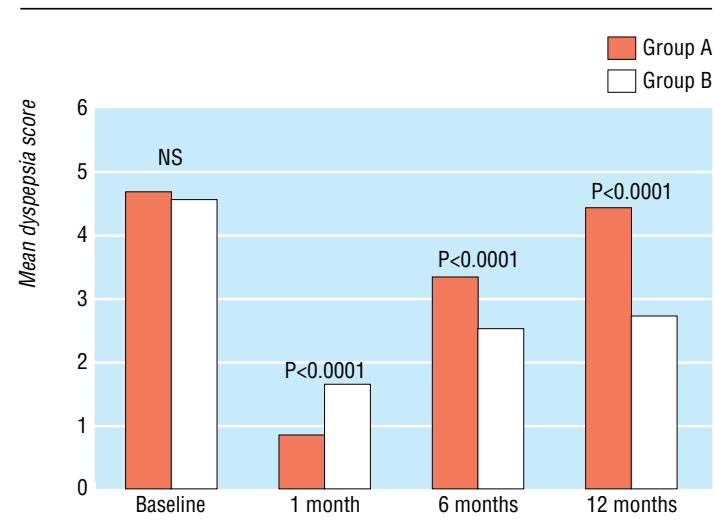

Fig 2 Mean dyspepsia scores over the various time points of the study in patients undergoing empirical treatment with omeprazole (group A) and a "test and treat" strategy (group B). Group B includes both patients who received eradication treatment for Helicobacter pylori infection and those who tested negative for the infection and received four weeks' treatment with omeprazole. (Data are expressed as mean and standard deviation; NS=not significant)

treatment and only $19(25 \%)$ of 77 patients in the proton pump inhibitor group showed recurrence of symptoms in the first two months. The difference was not significant owing to the small number of patients.

\section{Adherence to treatment and adverse events}

No patient was withdrawn as a result of poor adherence to drugs. Thirty six $(33 \%)$ patients in the omeprazole group and $40(36 \%)$ in the test and treat group reported at least one adverse event. Nausea, taste perversion, diarrhoea, and headache were the most common events reported. No patients had to stop their pills because of adverse events.

\section{Discussion}

We have compared two non-invasive empirical approaches to dyspepsia: a four week treatment with omeprazole and an initial non-invasive $H$ pylori test followed by eradication treatment for patients with a

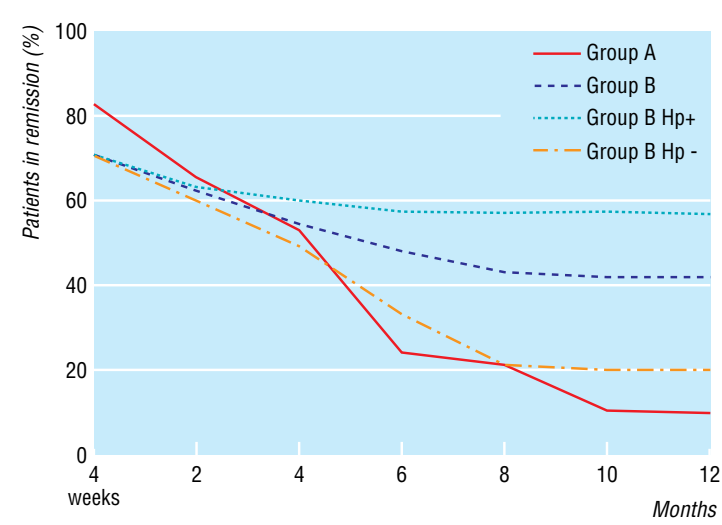

Fig 3 Symptom remission curves from 0 to 12 months of follow up. At the first visit for assessment, four weeks after the beginning of the treatment (time 0), 90/109 (83\%) patients in the omeprazole group (group A) and 78/110 (70.9\%) in the "test and treat" group (group B) were in remission. The curves for patients undergoing Helicobacter eradication treatment (Group B HP+, 47/67 in remission) and those who tested negative for $H$ pylori infection (Group B HP-, 31/43 in remission) and received omeprazole treatment are also shown positive test result and omeprazole alone for those with a negative test result. Our study shows that the test and treat strategy is more effective than treatment with a proton pump inhibitor in reducing rates of referral for endoscopy and in improving symptoms. Treatment with a proton pump inhibitor is effective in undiagnosed dyspepsia, ${ }^{5}$ but we have shown that after this approach about $88 \%$ of patients will undergo endoscopy: those who respond to the treatment (patients with gastro-oesophageal reflux disease, ulcer, or acid sensitive dyspepsia) whose symptoms recur when the treatment is discontinued and those who do not respond to the proton pump inhibitor.

\section{Effect on symptoms of dyspepsia}

After eradication of $H$ pylori, symptoms improved in a smaller number of patients (owing to the shorter proton pump inhibitor treatment), but after one year about $60 \%$ of the patients were still without symptoms. Most patients were affected by peptic ulcer, but some of them probably had functional dyspepsia. ${ }^{15}$ About 30\% of dyspeptic patients did not respond to the eradication treatment. Eight of them, however, reported improvement of their symptoms during the eradication treatment and then a relapse after discontinuation. Their symptoms are likely to respond to the omeprazole administered in the eradication regimen and, according to current knowledge, ${ }^{16}$ these patients probably have gastro-oesophageal reflux disease. We observed a symptomatic relapse within one year in only seven (15\%) of the 47 patients who responded to the eradication treatment. Some patients are likely to be affected by reflux disease, as indicated by the number of hiatus hernias observed at endoscopy, and responded to the omeprazole administrated in the eradication regimen. We excluded patients with reflux symptoms from our study, as $H$ pylori does not have a causative role in gastro-oesophageal reflux disease. Our data highlight some of the difficulties in making the clinical diagnosis of reflux disease. ${ }^{12}{ }^{17}$

\section{Diagnoses yielded by endoscopy}

We found no peptic ulcer in the patients in the test and treat group undergoing endoscopy. This is probably because patients with an ulcer have improved symptoms after healing of the lesion due to eradication. Treatment with a proton pump inhibitor fails to cure a significant proportion of patients with ulcer due to $H$ pylori. Furthermore, some patients whose ulcers have healed under treatment with proton pump inhibitor may have continued symptoms and be given an erroneous endoscopic diagnosis of functional disease. The number of duodenal scars found in the patients treated with omeprazole supports this theory.

The number of cases of oesophagitis diagnosed after proton pump inhibitor treatment was significantly lower than after eradication treatment. Casecontrol studies have shown that eradication of $\mathrm{H}$ pylori may result in an increased incidence of gastrooesophageal reflux disease. ${ }^{18}$ More recent data, however, do not support this hypothesis. ${ }^{12}{ }^{19}$ We believe that the four week proton pump inhibitor treatment is more efficient than the eradication treatment in terms of healing oesophageal erosions and persistence of symptomatic remission. This would lead to underestimation of the severity of gastro-oesophageal reflux disease. 


\section{Safety}

A main concern regarding the empirical treatment of dyspepsia is the possibility of missing gastric cancer. No gastric cancer was diagnosed or missed in our study. Although a delay in diagnosis of a few weeks does not affect the likelihood of cure of gastric cancer, a shorter empirical treatment is likely to represent a better option. After discontinuation of treatment in our study, symptoms recurred earlier in the patients who received eradication treatment than in those treated with proton pump inhibitor.

\section{Economic considerations}

The test and treat strategy is as efficient and safe as endoscopy in the management of patients with dyspepsia. ${ }^{20}{ }^{21}$ Conversely, the cost effective use of endoscopy is hotly debated. ${ }^{28-1122}$ Our study was not designed to estimate the cost effectiveness of the management strategies. In a public health perspective good clinical judgment, the patient's wishes, and the availability of resources will influence the choice of strategy. However, if we choose to offer an empirical treatment the test and treat strategy should be the preferred option.

\section{Generalisability of findings}

The test and treat strategy was superior to empirical treatment with omeprazole in our study population, but this advantage might be less evident in populations with a lower prevalence of $H$ pylori infection. A recent study shows that treatment with a proton pump inhibitor becomes less costly than the test and treat strategy when the prevalence of $H$ pylori is lower than $20 \% .^{23}$ The prevalence of $H$ pylori infection in our study was about $60 \%$, but we excluded patients with reflux symptoms, who have a lower prevalence of infection. ${ }^{24}$ Including patients with reflux symptoms, the preva-

\section{What is already known on this topic}

Dyspeptic patients aged under 45 without alarm symptoms are unlikely to have a malignancy

An empirical prescribing approach has been recommended as a way to reduce endoscopic workload

The "test for Helicobacter pylori and treat" strategy and acid suppressing drugs have both been recommended for uninvestigated dyspepsia, but no randomised controlled trials have compared the two approaches

\section{What this study adds}

Treatment to eradicate $H$ pylori allows the resolution of symptoms in a large number of dyspeptic patients and reduces the endoscopic workload

Treatment with omeprazole is likely to mask an appreciable number of peptic ulcers and cases of oesophagitis

The $H$ pylori test and treat strategy should be the preferred approach to dyspepsia, if we choose to perform an empirical treatment. lence of infection in our dyspepsia population would be $55 \%,{ }^{25}$ similar to the value of $55.2 \%$ reported in a large meta-analysis. ${ }^{26}$

Although our study took place in a hospital clinic, we consider the results to be applicable to primary care patients. As a reference centre for dyspepsia, we invited primary care doctors to refer their uninvestigated patients to us, so our patients are likely to be similar to those seen in the primary care setting. We believe, however, that our findings would need to be assessed in the primary care setting before implementation is considered.

Contributors: GM designed and managed the study. AM and CdeN contributed to the conduct of the study. GM and AB wrote the paper. $\mathrm{AB}$ is the guarantor.

Funding: No pharmaceutical company or other commercial entity provided funding or other resources for the study.

Competing interests: None declared.

Ethical approval: The local ethics committee approved the trial.

1 Health and Public Policy Committee, American College of Physicians. Endoscopy in the evaluation of dyspepsia. Ann Intern Med 1985;102:266-9.

2 Bytzer P, Hansen JM, Schaalitzky de Muckadell OB. H2-blocker therapy or prompt endoscopy in management of dyspepsia. Lancet 1994:343:811-6

3 European Helicobacter Pylori Study Group. Current European concepts in the management of Helicobacter pylori infection: the Maastricht consensus report. Gut 1997;41:8-13.

4 Nyren O, Adami HO, Bates S, Bergstrom R, Gustavsson S, Loof L, et al. Absence of therapeutic benefit from antacids or cimetidine in non-ulcer dyspepsia. N Engl J Med 1986;314:339-43.

5 Jones RH, Baxter G. Lansoprazole $30 \mathrm{mg}$ daily versus ranitidine $150 \mathrm{mg}$ b.d. in the treatment of acid related dyspepsia. Aliment Pharmacol Ther 1997;11:541-6.

6 Graham DY, Lew GM, Klein PD, Evans DG, Evans DJ Jr, Saeed ZA, et al. Effect of treatment of Helicobacter pylori infection on the long-term recurrence of gastric or duodenal ulcer: a randomised, controlled study. Ann Intern Med 1992;116:705-8.

7 Marshall BJ, Goodwin CS, Warren JR, Murray R, Blincow ED, Blackbourn $\mathrm{SJ}$, et al. Prospective double-blind trial of duodenal ulcer relapse after eradication of Campylobacter pylori. Lancet 1988;2:1437-42.

8 Fendrick AM, Chernew ME. Hirth RA, Bloom BS. Alternative management strategies for patients with suspected peptic ulcer disease. Ann Intern Med 1995;123:260-8.

9 Silverstein MD, Petterson T, Talley NJ. Initial endoscopy or empirical therapy with or without testing for Helicobacter pylori for dyspepsia: a therapy with or without testing for Helicobacter $\mathrm{Py}$

10 Ofman JJ, Etchason J, Fullerton S, Kahn KL, Soll AH. Management strategies for Helicobacter pylori seropositive patients with dyspepsia: clinical and economic consequences. Ann Intern Med 1997;126:280-91.

11 Sonnenberg A. Cost-benefit analysis of testing for Helicobacter pylori in dyspeptic subjects. Am J Gastroenterol 1996;91:1773-7.

12 Manes G, Mosca S, deNucci C, Lombardi G, Lioniello M, Balzano A. High prevalence of reflux symptoms in duodenal ulcer patients who develop gastro-oesophageal reflux disease after curing Helicobacter pylori infection. Digest Liver Dis 2001;33:665-70.

13 Boyce HW. Hiatal hernia and peptic disease of the esophagus. In: Sivak MV, ed. Gastroenterologic endoscopy. Philadelphia: Saunders, 1987.

14 Johnson NJ, Boyd EJ, Mills JG, Wood JR. Acute treatment of reflux oesophagitis: a multicentre trial to compare $150 \mathrm{mg}$ ranitidine b.i.d. with $300 \mathrm{mg}$ ranitidine q.d.s. Aliment Pharmacol Ther 1989;3:259-66.

15 McCollK, Murray L, El-Omar E, Dickson A, El-Nujumi A, Wirz A, et al. Symptomatic benefit from eradicating Helicobacter pylori infection in patients with nonulcer dyspepsia. N Engl J Med 1998;339:1869-74.

16 Fass R, Ofman JJ, Gralnek IM, Johnson C, Camargo E, Sampliner RE, et al. Clinical and economic assessment of the omeprazole test in patients with symptoms suggestive of gastroesophageal reflux disease. Arch Intern Med 1999;159:2161-8.

17 Carlsson R, Dent J, Bolling-Sternevald E, Johnsson F, Junghard O, Lauritsen $\mathrm{K}$, et al. The usefulness of a structured questionnaire in the assessment of symptomatic gastroesophageal reflux disease. Scand J Gasassessment of symptomatic

18 Labenz J, Blum AL, Bayerdoerffer E, Meining A, Stolte M, Borsch G. Curing Helicobacter pylori infection in patients with duodenal ulcer may provoke reflux oesophagitis. Gastroenterology 1997;112:1442-7.

19 Moayyedi P, Bardhan C, Young L, Dixom MF, Brown L, Axon ATR. Helicobacter pylori eradication does not exacerbate reflux symptoms in gastroesophageal reflux disease. Gastroenterology 2001;121:1120-6.

20 Lassen AT, Pedersen FM, Bytzer P, Shaffalitzky de Muckadell OB. Helicobacter pylori test-and-eradicate versus prompt endoscopy for management of dyspeptic patients: a randomised trial. Lancet 2000;356:455-60.

21 McColl KEL, Murray LS, Gillen D, Walker A, Wirz A, Fletcher J, et al. Randomised trial of endoscopy with testing for Helicobacter pylori compared with non-invasive $\mathrm{H}$ pylori testing alone in the management of dyspepsia. BMJ 2002; 324: 999-1002. 
22 Heaney A, Collins JSA, Watson RPG, McFarland RJM, Bamford KB, Tham TCK. A prospective randomised trial of a "test-and-treat" policy versus endoscopy based management in young Helicobacter pylori positive patients with ulcer-like dyspepsia, referred to a hospital clinic. Gut 1999;45:186-90.

23 Ladabaum U, Chey WD, Scheiman JM, Fendrick AM. Reappraisal of non-invasive management strategies for uninvestigated dyspepsia: a costminimization analysis. Aliment Pharmacol Ther 2002;16:1491-501.

24 Vicari JJ, Peek RM, Falk GW, Goldblum JR, Easley KA, Schnell J, et al. The seroprevalence of cagA-positive Helicobacter pylori strains in the spectrum of gastroesophageal reflux disease. Gastroenterology 1998;115:50-7.

25 Manes G, Mosca S, Laccetti M, Lioniello M, Balzano A. Helicobacter pylori infection, pattern of gastritis and symptoms in erosive and nonerosive gastroesophageal reflux disease. Scand J Gastrentero 1999;34:658-62

6 Jaakkimainen RL, Boyle E, Tudiver F. Is Helicobacter pylori associated with non-ulcer dyspepsia and will eradication improve symptoms? A meta-analysis. BMJ 1999;319:1040-4.

(Accepted 4 April 2003) 